\title{
What do we know about assessing healthcare students and professionals' knowledge, attitude and practice regarding female genital mutilation? A systematic review
}

Jasmine Abdulcadir ${ }^{1,2^{*}}$, Lale Say ${ }^{2}$ and Christina Pallitto ${ }^{2}$

\begin{abstract}
Introduction: Improving healthcare providers' capacities of prevention and treatment of female genital mutilation (FGM) is important given the fact that 200 million women and girls globally are living with FGM. However, training programs are lacking and often not evaluated. Validated and standardized tools to assess providers' knowledge, attitude and practice (KAP) regarding FGM are lacking. Therefore, little evidence exists on the impact of training efforts on healthcare providers' KAP on FGM. The aim of our paper is to systematically review the available published and grey literature on the existing quantitative tools (e.g. scales, questionnaires) measuring healthcare students' and providers' KAP on FGM.

Main body: We systematically reviewed the published and grey literature on any quantitative assessment/ measurement/evaluation of KAP of healthcare students and providers about FGM from January $1^{\text {st }}, 1995$ to July $12^{\text {th }}, 2016$. Twenty-nine papers met our inclusion criteria. We reviewed 18 full text questionnaires implemented and administered to healthcare professionals (students, nurses, midwives and physicians) in high and low income countries. The questionnaires assessed basic KAP on FGM. Some included personal and cultural beliefs, past clinical experiences, personal awareness of available clinical guidelines and laws, previous training on FGM, training needs, caregiver's confidence in management of women with FGM, communication and personal perceptions. Identified gaps included the medical, psychological or surgical treatments indicated to improve girls and women's health; correct diagnosis, recording ad reporting capacities; clitoral reconstruction and psychosexual care of circumcised women. Cultural and personal beliefs on FGM were investigated only in high prevalence countries. Few questionnaires addressed care of children, child protection strategies, treatment of short-term complications, and prevention.

(Continued on next page)
\end{abstract}

\footnotetext{
* Correspondence: jasmine.abdulcadir@hcuge.ch

${ }^{1}$ Department of Obstetrics and Gynecology, Geneva University Hospitals,

Faculty of Medicine, University of Geneva, 30 Bld de la Cluse, 1211 Geneva,

Switzerland

${ }^{2}$ Department of Reproductive Health and Research, World Health

Organization, 20, Avenue Appia, 1211 Geneva, Switzerland
} 
(Continued from previous page)

Conclusion: There is a need for implementation and testing of interventions aimed at improving healthcare professionals' and students' capacities of diagnosis, care and prevention of FGM. Designing tools for measuring the outcomes of such interventions is a critical aspect. A unique, reproducible and standardized questionnaire could be created to measure the effect of a particular training program. Such a tool would also allow comparisons between settings, countries and interventions. An ideal tool would test the clinical capacities of providers in managing complications and communicating with clients with FGM as well as changes in KAP.

Keywords: Female genital mutilation, Female genital cutting, FGM, Questionnaires, KAP, Knowledge, Attitude, Practice, Caregivers, Healthcare professionals

\section{Plain English summary}

Improving healthcare students and providers' capacities of prevention and treatment of female genital mutilation (FGM) is important given the fact that 200 million women and girls globally are living with FGM. However, training programs and validated and standardized tools to assess providers' knowledge, attitude and practice regarding FGM are lacking. Therefore, little evidence exists on the impact of training efforts on healthcare providers on FGM.

Our paper reviews the available literature on the existing quantitative tools (e.g. scales, questionnaires) measuring healthcare students' and providers' knowledge, attitude and practice on FGM. We reviewed 18 full text questionnaires implemented and administered to healthcare students' and professionals in high and low income countries. The questionnaires assessed basic knowledge, attitude and practice on FGM. Some included personal and cultural beliefs, past clinical experiences, personal awareness of guidelines and laws, previous training on FGM, training needs, caregiver's confidence in management of women with FGM, communication and personal perceptions. Identified gaps included the medical, psychological or surgical treatments indicated to improve girls and women's health; correct diagnosis and psychosexual care of women who have undergone FGM. Cultural and personal beliefs on FGM were investigated only in high prevalence countries. Few questionnaires addressed care of children, child protection strategies, treatment of shortterm complications, and prevention.

There is a need for implementation and testing of interventions aimed at improving healthcare students' and professionals' capacities of diagnosis, care and prevention of FGM. Designing a standardized tool for measuring the impact of interventions aimed at health care providers would generate evidence on what works to improve care for women and girls living with FGM.

\section{Background}

Female Genital Mutilation (FGM) is not included in most of the pre- and post-graduate curricula of health care providers [1]. The new guidelines of the World
Health Organization (WHO) on the management of FGM complications recommend that healthcare providers be trained so that they are able to offer evidence based and respectful information, health education and care to girls and women living with FGM [2]. According to $\mathrm{WHO}$, training could also increase prevention capacities and decrease the "medicalization" of FGM, which is defined as genital cutting by a healthcare provider in any setting and at any point in a woman's life [2].

Healthcare professionals have a key role in providing informed care, which includes identifying and treating psychological and physical health consequences of FGM; as well as in recording the practice in medical files, reporting it to authorities where appropriate and preventing the practice from being carried out. Health care providers often receive little to no training on how to provide care and treatment to women and girls with FGM, and when training does occur [3], the clinical, epidemiological and legal impact of training on healthcare professionals' knowledge, practice and attitude is rarely assessed. A recent systematic review of the published and grey literature on the interventions aimed at improving healthcare providers' capacities of prevention and treatment of FGM found only two studies reporting improvement in knowledge of the practice and confidence in treating it among participants [4], showing the lack of evidence on existing training programs [5].

The aim of our paper is to systematically review the available published and grey literature on the existing quantitative tools (e.g. scales, questionnaires) measuring healthcare students' and providers' knowledge, attitude and practice (KAP) regarding FGM. The paper will summarize the available existing tools, discuss gaps in evidence and will inform the development of a unique, standardized, comprehensive instrument to evaluate training interventions in low and high income countries.

\section{Methods}

The present systematic review was conducted following the PRISMA (Preferred Reporting Items for Systematic reviews and meta-Analyses) guidelines [6]. The available published and grey literature on assessing healthcare 
students and providers' knowledge, attitude and practice regarding female genital mutilation was identified using a protocol designed for this purpose. The protocol is available on request. The systematic search included two online databases: Pubmed/Medline and Popline. We considered publications from January $1^{\text {st }}, 1995$ to July $12^{\text {th }}, 2016$. The keywords used in the search were "female genital mutilation", "female genital cutting", "female circumcision", "infibulation", "excision", "female genital mutilation/cutting", "health personnel", "healthcare providers", "nurses", "midwives", "doctors", "community health workers", "physicians", "education", "training", "guidelines", "knowledge", "attitude", "intervention", "practice", "questionnaire", "interview", "survey". The terms were used in various combinations. Hand searching was performed through the reference list of the relevant papers. When the actual tools used to assess knowledge, practice and attitude were not available in the papers, the authors were contacted by email to request a copy.

We had no language restriction and included any study design that reported any quantitative assessment/ measurement/evaluation of knowledge, attitude and practice of healthcare providers about FGM. To ensure a comprehensive overview of existing tools and to inform the development of a future instrument, we searched for relevant papers published during the past 21 years in Pubmed and Popline.
JA retrieved, screened the studies for relevance to the research question and extracted data from the included studies.

\section{Results}

Our search yielded 199 publications eligible for screening. After title and abstract screening, 55 articles were included for full text review. Twenty-nine of these met our inclusion criteria (Fig. 1). We had access to the full text of the quantitative assessment tools employed to measure knowledge, attitude and practice of healthcare students and professionals in 19 of these papers (18 distinct questionnaires as two of the papers presented the same tool) (Table 1) [7, 8]. In spite of multiple efforts to locate the remaining questionnaires, we were unable to retrieve them. Of the tools we could not access, many were from high prevalence African countries: Egypt [9-14], Mali [15], Nigeria [16, 17] and Sudan [18]. The remaining two unavailable tools had been administered in Sweden [19] and UK [20]. The available questionnaires we fully reviewed were from the UK [21-23], Australia [24, 25], Belgium [26, 27], Switzerland [28, 29], the U.S. [30, 31], Spain [32], Sweden [33], the Gambia (same questionnaire in two included studies) $[7,8]$, Nigeria [34] and Sudan [35].

The questionnaires identified focused on basic assessment of knowledge, attitude and practice regarding

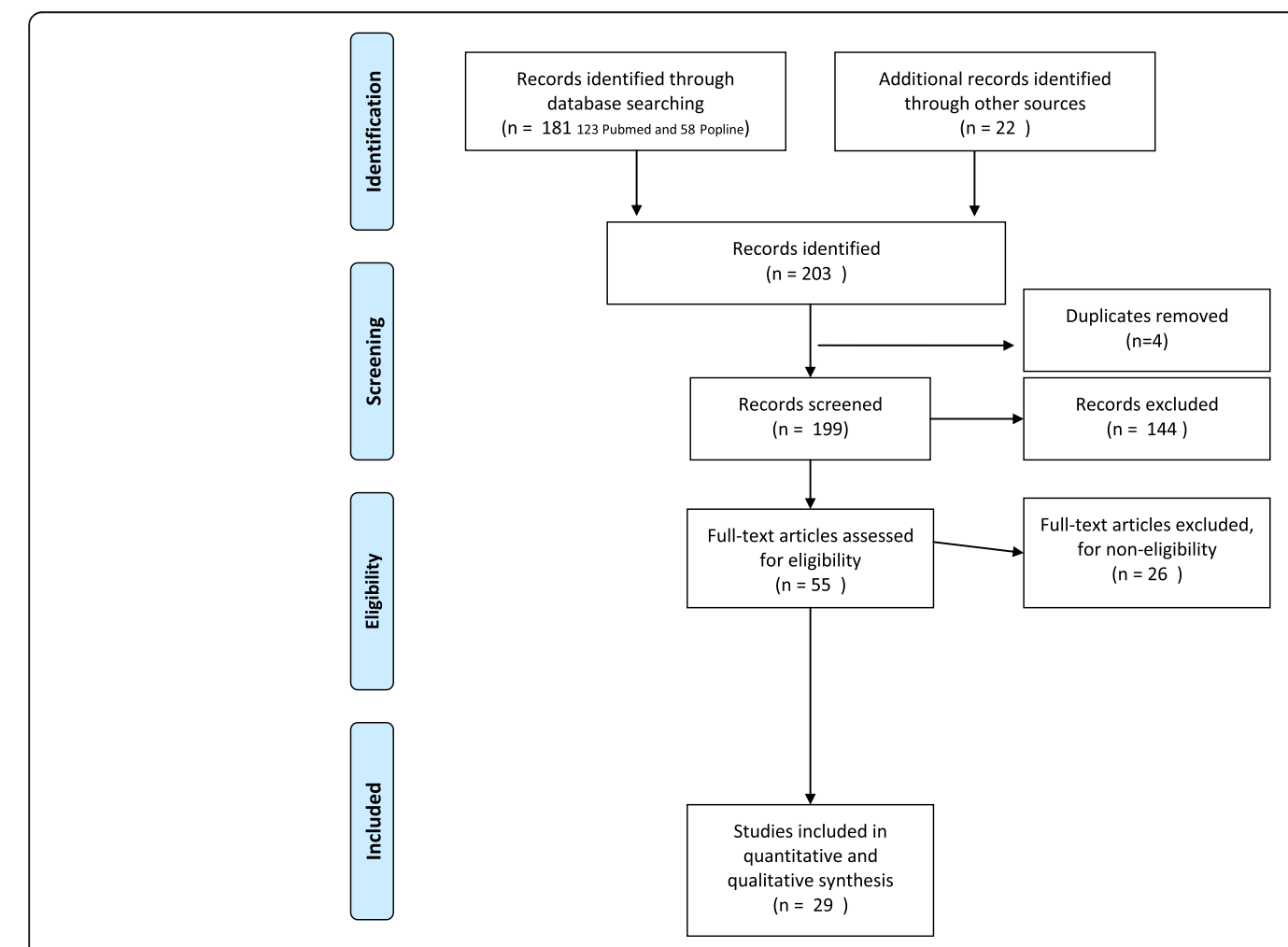

Fig. 1 PRISMA 2009 flow diagram 


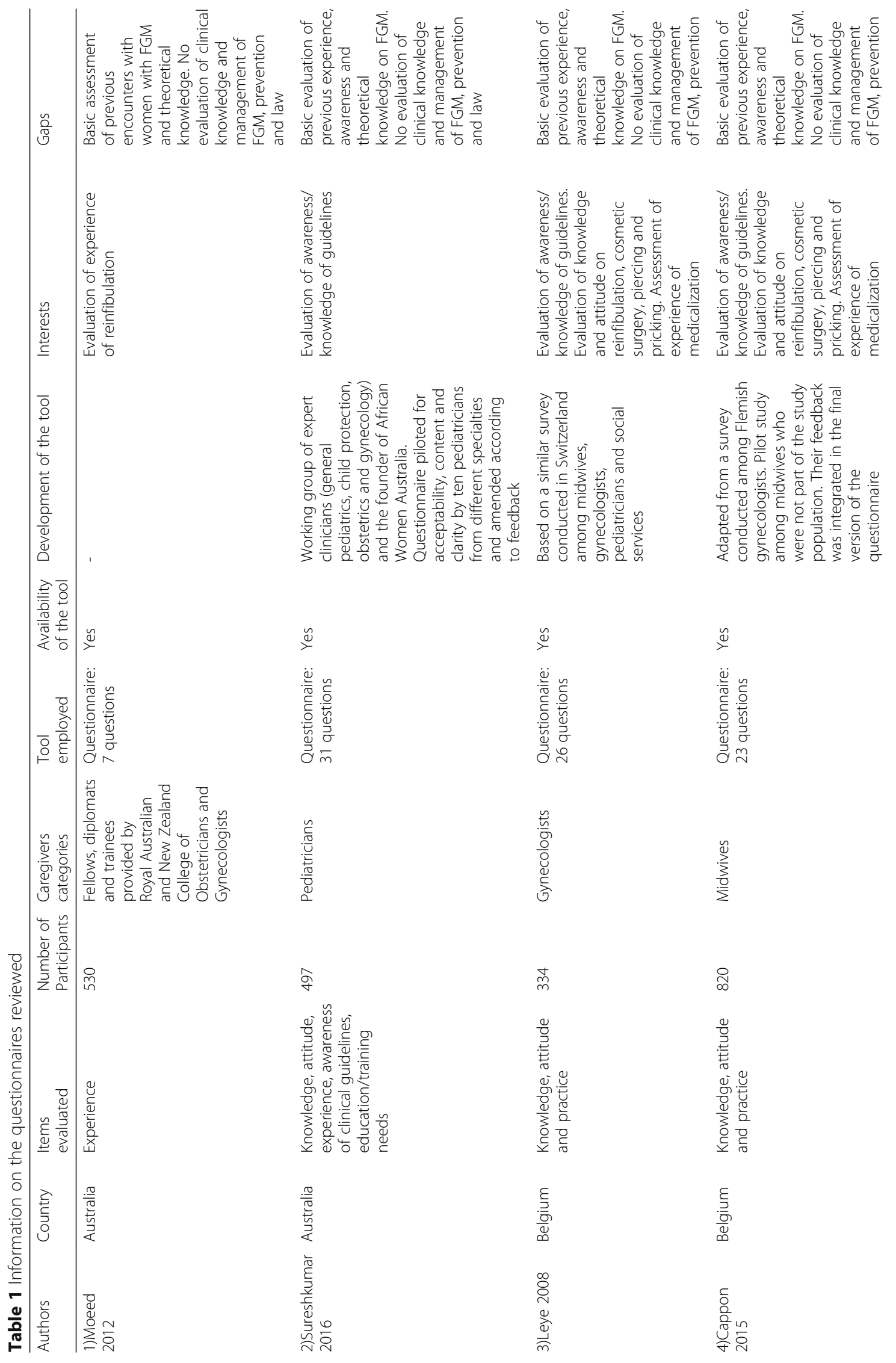




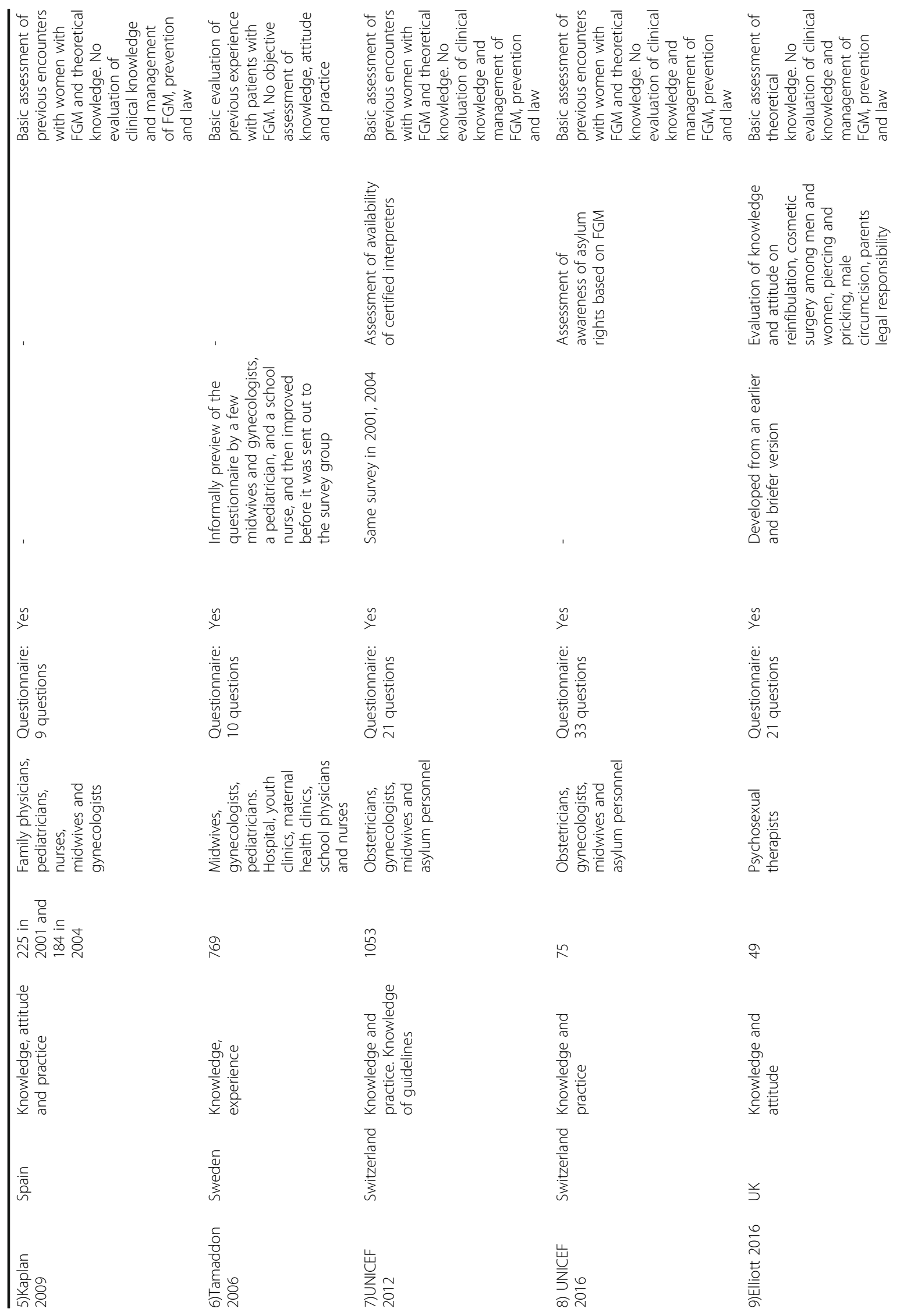




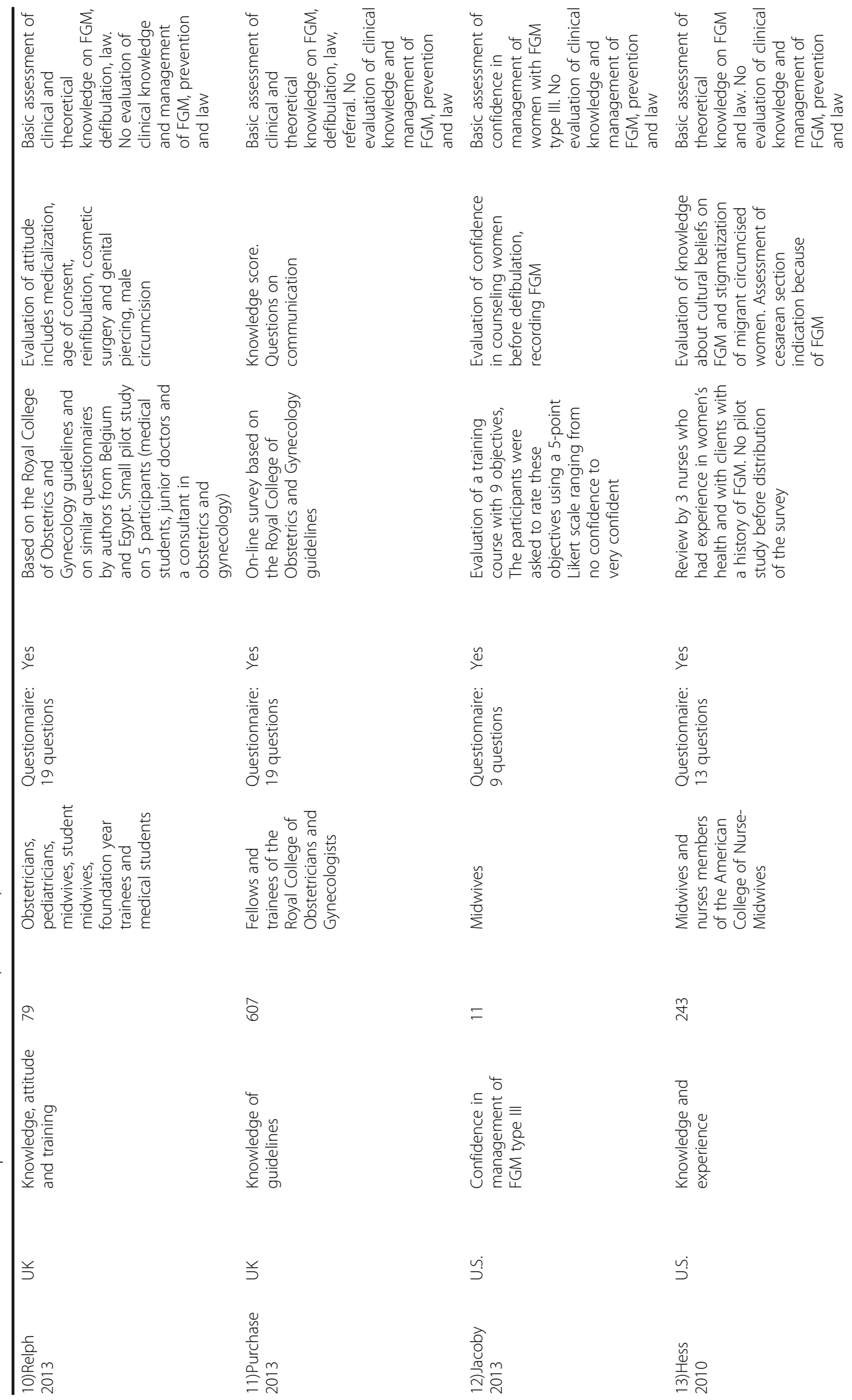




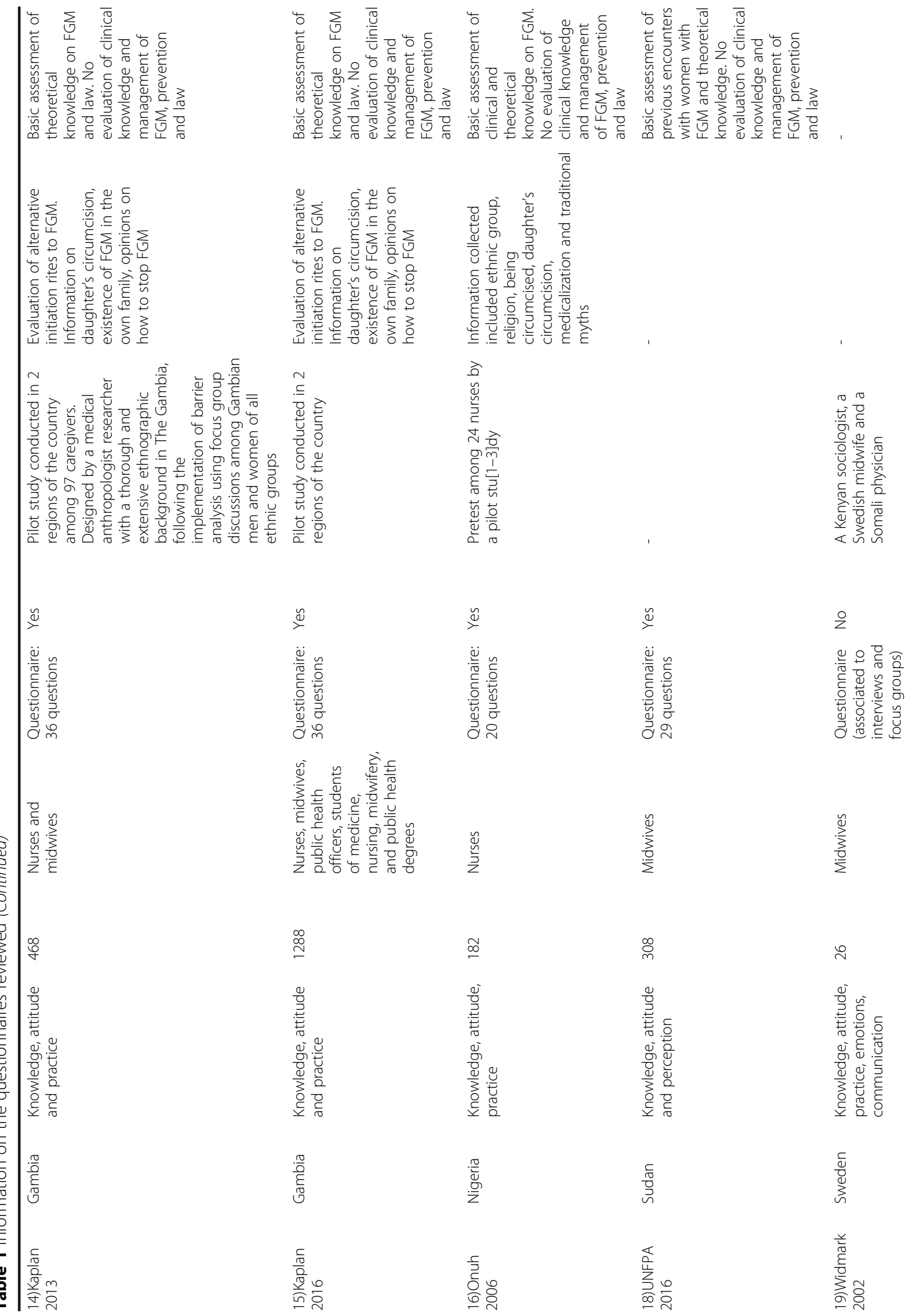


ᄃ

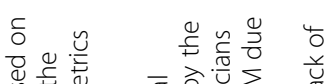

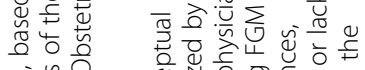

ज饮

可苋

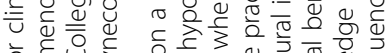

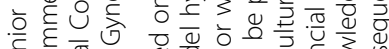

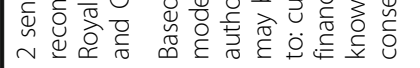

离

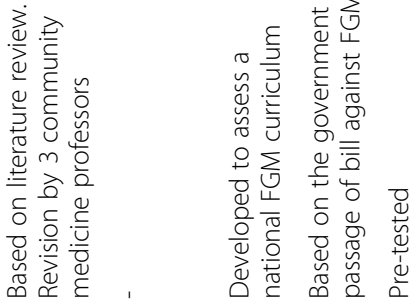

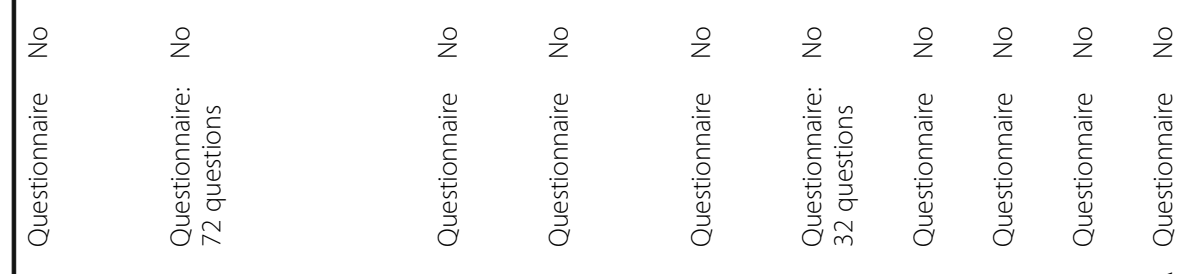

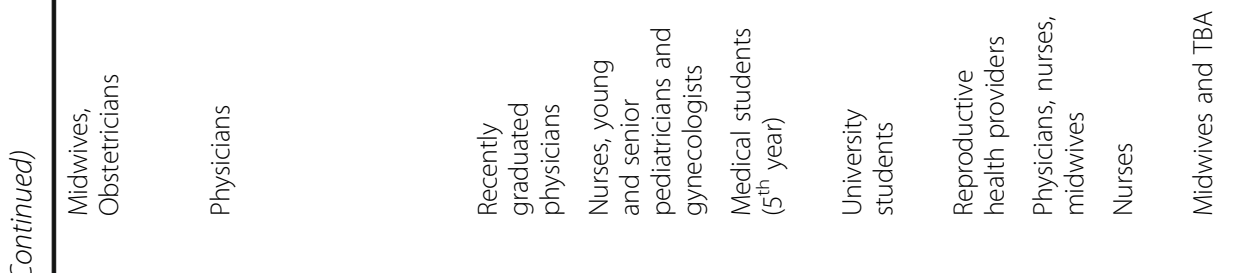

\begin{tabular}{|c|c|c|c|c|c|c|c|c|c|}
\hline ๒ุ & $\stackrel{n}{\sigma}$ & ㅇํ & $\bar{\infty}$ & $\stackrel{\text { m }}{\text { re }}$ & $\stackrel{?}{\circ}$ & $\stackrel{\text { I }}{ }$ & $\stackrel{\text { ㄱำ }}{\sim}$ & 율 & $\stackrel{n}{n}$ \\
\hline 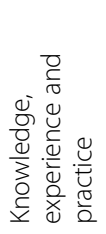 & 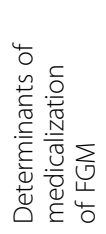 & 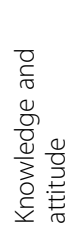 & 军 & 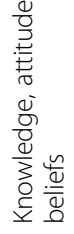 & 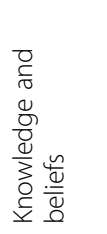 & 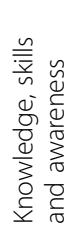 & 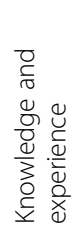 & 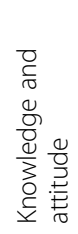 & 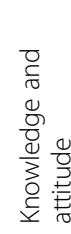 \\
\hline 弚 & 蒿 & 䓂 & 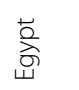 & 苍 & 茁 & $\frac{\overline{\bar{\pi}}}{\sum^{\frac{\pi}{2}}}$ & 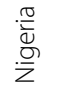 & $\begin{array}{l}\frac{\pi}{\bar{U}} \\
\frac{0}{2}\end{array}$ & 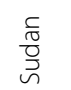 \\
\hline 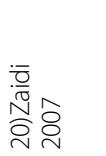 & 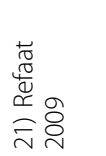 & 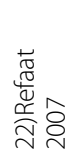 & 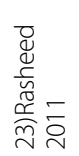 & 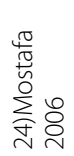 & 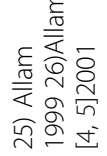 & 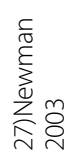 & 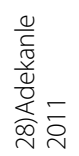 & 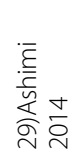 & s \\
\hline
\end{tabular}


FGM. Subjects included existing types of FGM, main physical complications, knowledge of countries and religions where FGM is practiced, cultural reasons for genital cutting, defibulation, obstetric care in the event of FGM and reinfibulation.

Some tools enquired about past clinical experiences and encounters with women with FGM, personal awareness of available clinical guidelines and local laws, previous training on FGM, training needs, caregiver's confidence in clinical management of women with FGM, communication with clients and personal perceptions when caring for women living with FGM.

Healthcare providers' feelings about women with FGM were investigated by only one questionnaire, which was administered to midwives in Sweden (full text unavailable for the review) [19]. The personal and cultural beliefs on FGM and the presence of genital cutting in one's own family were only asked in studies conducted in African countries, where FGM was considered a traditional practice. Cultural beliefs of healthcare professionals regarding women with FGM were not assessed in high income countries.

Determinants of medicalization were investigated in both high and low income countries. In the UK and in Belgium, some specific topics covered included highly debated subjects such as medical and legal controversies regarding FGM and cosmetic surgery, appropriate terminology to use when speaking to a woman affected by FGM, personal opinions concerning pricking and piercing classified as FGM type IV and differences between FGM and male circumcision [21, 22, 26, 27].

The questionnaires used in Switzerland asked caregivers about the availability of certified interpreters when caring for women with FGM and on awareness of asylum rights related to genital cutting [28, 29].

Kaplan and colleagues' conducting research in the Gambia asked healthcare professionals about their attitude concerning alternative initiation rites and discrimination of uncut girls/women $[7,8]$.

The areas of knowledge, attitude and practice identified in the different questionnaires are illustrated in Table 2.

The questionnaires identified in the present systematic review were administered to a range of populations, including university students, nurses, midwives and physicians (general practitioners, obstetricians and gynecologists, pediatricians and fellows in these specializations). Psychosexual therapists were included only in UK [21], social workers and asylum personnel in Switzerland, public health workers in the Gambia $[8,28,29]$ and traditional birth attendants in Sudan (full text questionnaire unavailable) [18].

The number of respondents varied from 11 [31] to 1288 people [8]. The length of the assessment tools ranged from 7 [24] to 36 questions [7, 8]. One unavailable questionnaire focusing on medicalization of FGM in Egypt included 72 questions [14]. Response options included multiple choice, free text or Likert scales.

The questionnaires reviewed were generally developed by experts in FGM and were based on local clinical recommendations/guidelines on FGM. In agreement with such resources, the main expectations regarding KAP of the healthcare professionals interviewed were for instance not performing C-section in case of FGM type III; offering defibulation to treat or avoid urogynecological, sexual and obstetric complications; being against reinfibulation and any form of medicalization; being aware that FGM is illegal, a human rights violation and a dangerous practice responsible for several short and long term complications. Some of the questionnaires were informally piloted or pre-tested for acceptability, content, clarity and feedback in small groups of caregivers or students $[7,8,17,23,25,26,33,34]$. Only two questionnaires, implemented in Belgium and U.K., were based on previous questionnaires used in another country $[23,27]$. The questionnaires were administered in person, generally by medical students or midwives trained to administer the questionnaire, or by email or postal mail.

Only in Switzerland, Belgium and the Gambia the questionnaires were administered more than once [7, 8, 26-29]. Two papers reported administering the same instrument to assess an improvement of knowledge, attitude and practice after a training intervention $[21,31]$.

\section{Discussion}

Several questionnaires have been developed and used in low/middle (LMIC) and high income countries (HIC) to assess knowledge, attitude, experience, beliefs and practice of healthcare professionals regarding FGM. The main contents of these questionnaires were similar regardless of setting (LMIC and HIC), which included high prevalence countries in Africa and countries of the diaspora. No studies of this kind were conducted in other high prevalence countries outside of Africa, such as Indonesia and Malaysia.

The main gap identified in the questionnaires, which reflects the gap in training, relates to the assessment of clinical management of women with FGM to prevent and treat complications. Questionnaires tended to enquire about existing types and complications of FGM rather than about the medical, psychological or surgical treatments indicated to improve girls and women's health. Knowledge of defibulation, in particular during pregnancy, as a specific treatment option was assessed in some questionnaires. There was little assessment of the accuracy of diagnosis, recording capacities, clitoral reconstruction and psychosexual care of affected women. 


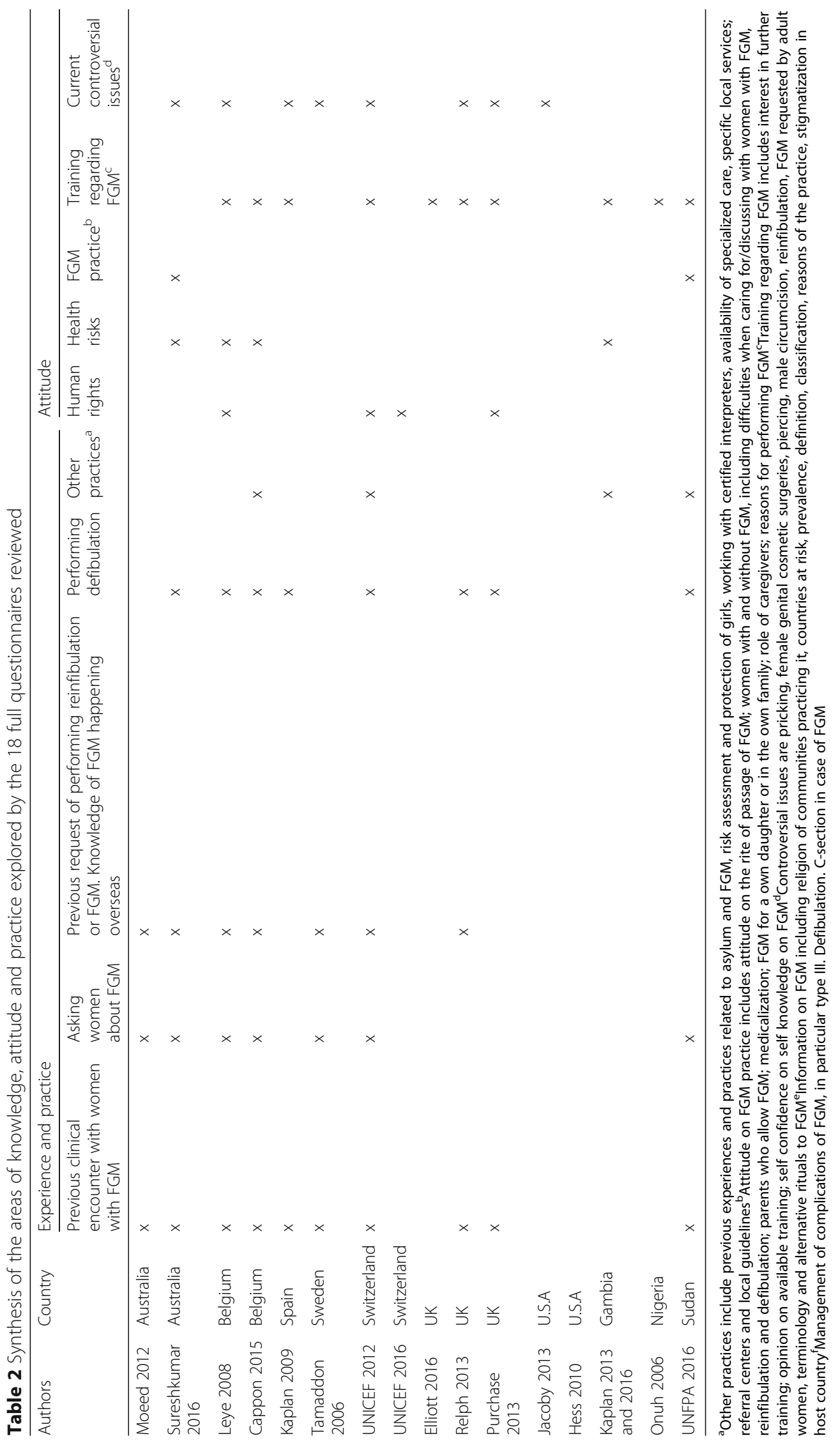




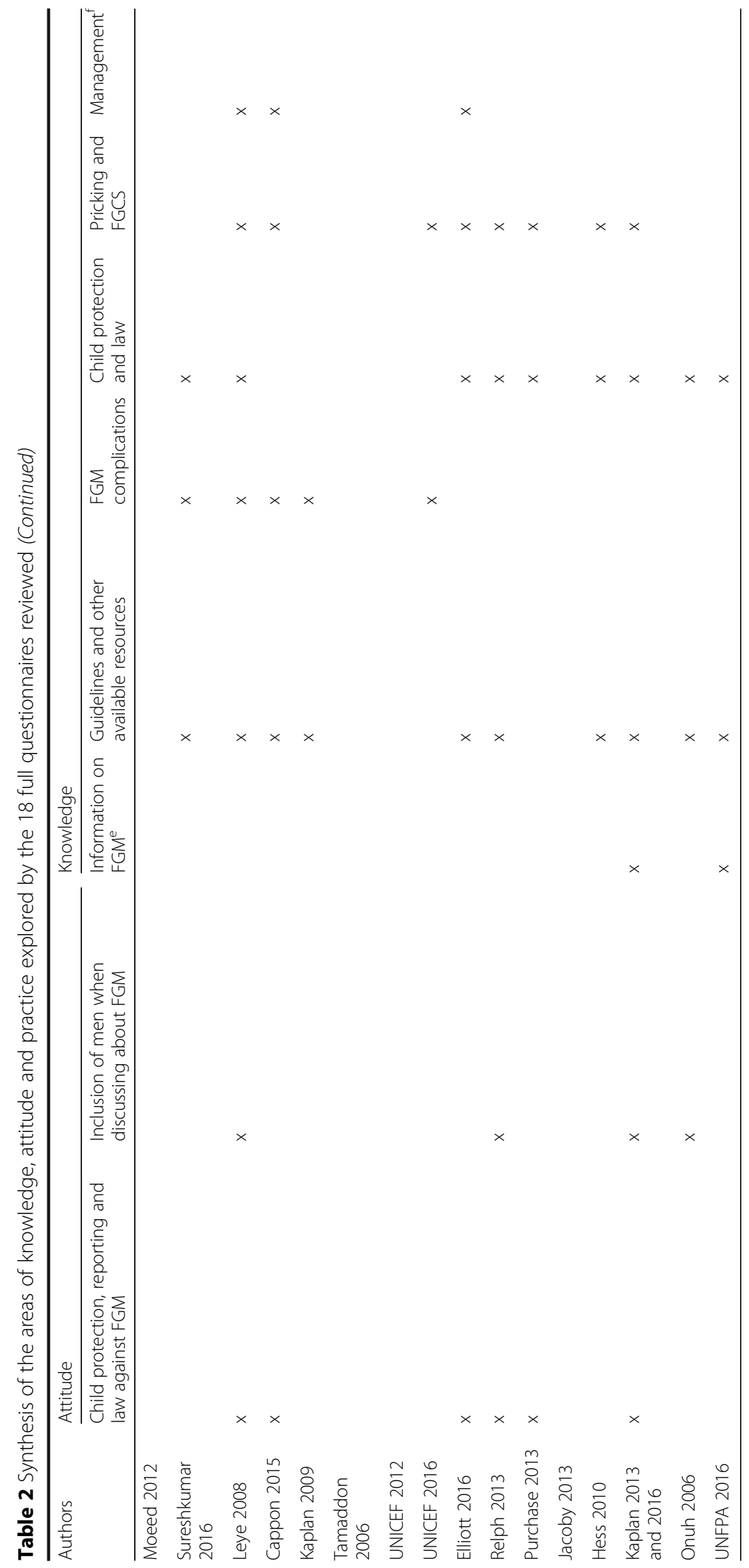


Cultural and personal beliefs on cut and uncut women were investigated only in high prevalence countries and never in high income countries despite the fact that providers in host countries may also hold false beliefs that could negatively affect healthcare. The care of children with FGM who present with short term complications were not investigated in most of the questionnaires. Knowledge or actions around child protection strategies were also rarely assessed. In addition, there was little attention to prevention of FGM and about potential strategies that health care providers could take to prevent FGM.

Although several questionnaires exist, authors tended to develop new measurement tools, which they did not use more than once in most of the settings. With the exception of two questionnaires, all of the instruments were used to assess caregivers' knowledge, attitude and practice. Only in U.S. and U.K. were questionnaires administered at baseline and after a training intervention to evaluate a potential improvement among the health care providers [21, 31]. Assessing healthcare providers' KAP is different than evaluating learning, learning transfer and the impact of a training, in particular on practice and in the long term. In addition, KAP assessments should be associated with or followed by health professionals support and training.

The review of the instruments revealed that there were no comparisons made between different populations of caregivers, settings and countries. LMIC and HIC providers could differ in KAP, cultural and traditional views and available resources. This implies differences in training and support needs. One of the examples is the FGM "medicalization" in high prevalence countries such as Egypt and Sudan, which has been explained by social pressure, the belief that a medicalized genital cutting reduces harm and dangers, financial reasons or lack of laws forbidding FGM [36]. Training on when to perform defibulation during pregnancy or labour might also be adapted depending on women's patterns of accessing care for antenatal care and during labour depending on the setting.

Statistical analyses to explore potential associations or correlations between the training of caregivers and their clinical practice or attitude were not conducted in any of the studies. Therefore, there is a lack of rigorous evidence on the impact of existing training programs on actual practice.

\section{Conclusion}

The review confirmed the need for education and training of healthcare professionals $[1,37]$, who are key persons in the care of complications and prevention of FGM. Interventions aimed at improving health providers' knowledge, skills, attitude, communication and prevention have been developed and implemented worldwide [3], but these often vary in quality and content. Furthermore, the effect of these trainings on clinical practice is unknown because of the lack of rigorous evaluation of acceptability and efficacy. A unique, validated and reproducible questionnaire to measure the impact of training interventions would facilitate the evaluation of future training and would also allow comparisons between different settings, interventions and countries. Such a tool could be progressively improved based on the experiences during its use. A standardized tool should test the real clinical and communication capacities of providers in managing complications of clients with FGM, while also assessing other aspects of care including attitude, practice, experience, prevention and legal considerations. Designing a standardized tool for measuring the outcomes of such interventions would increase evidence on existing programs, which would help to improve these programs and ultimately improve care of the millions of women and girls living with FGM.

\section{Abbreviations \\ FGM: Female genital mutilation; TBA: Traditional birth attendants; WHO: World Health Organization}

\section{Acknowledgements \\ None. \\ Funding \\ WHO. \\ Availability of data and materials \\ The data analyzed during the current study are available from the corresponding author on reasonable request.}

\section{Authors' contributions}

All: conception and planning. JA: carrying out the research. JA, CP: analyzing and writing up the results. All: revision and final approval. CP and LS are WHO staff members. The views expressed in this document are solely the responsibility of the authors and do not necessarily represent the views of the World Health Organization or its member countries. All authors read and approved the final manuscript.

\section{Competing interests}

The authors declare that they have no competing interests.

Consent for publication

N/A.

Ethics approval and consent to participate N/A.

\section{Publisher's Note}

Springer Nature remains neutral with regard to jurisdictional claims in published maps and institutional affiliations.

Received: 27 January 2017 Accepted: 25 April 2017

Published online: 22 May 2017

\section{References}

1. Dawson A, Homer CS, Turkmani S, Black K, Varol N. A systematic review of doctors' experiences and needs to support the care of women with female genital mutilation. Int J Gynaecol Obstet. 2015;131(1):35-40.

2. WHO Guidelines Approved by the Guidelines Review Committee. WHO Guidelines on the Management of Health Complications from Female Genital Mutilation. Geneva: World Health Organization Copyright (c); 2016 World Health Organization 2016. 
3. NHS. E-learning to improve awareness and understanding of FGM 2014 [cited 2016 17.10]. Available from: http://www.e-Ifh.org.uk/programmes/ female-genital-mutilation/.

4. Balfour J, Abdulcadir J, Say L, Hindin MJ. Interventions for healthcare providers to improve treatment and prevention of female genital mutilation: a systematic review. BMC Health Serv Res. 2016;16(1):409.

5. Abdulcadir J, Rodriguez MI, Say L. Research gaps in the care of women with female genital mutilation: an analysis. BJOG. 2015;122(3):294-303.

6. Moher D, Liberati A, Tetzlaff J, Altman DG. Preferred reporting items for systematic reviews and meta-analyses: the PRISMA statement. PLoS Med. 2009;6(7):e1000097.

7. Kaplan A, Hechavarria S, Bernal M, Bonhoure I. Knowledge, attitudes and practices of female genital mutilation/cutting among health care professionals in The Gambia: a multiethnic study. BMC Public Health. 2013;13:851.

8. Kaplan Marcusan A, Riba Singla L, Laye M, Secka DM, Utzet M, Le Charles MA. Female genital mutilation/cutting: changes and trends in knowledge, attitudes, and practices among health care professionals in The Gambia. Int J Womens Health. 2016;8:103-17.

9. Allam MF, de Irala-Estevez J, Fernandez-Crehuet Navajas R. Serrano de Castillo A, Hoashi JS, Pankovich MB, et al. Factors associated with the condoning of female genital mutilation among university students. Public Health. 2001;115(5):350-5.

10. Allam MF, de Irala-Estevez J, Navajas RF, del Castillo AS, Hoashi JS, Pankovich MB, et al. Students' knowledge of and attitudes about female circumcision in Egypt. N Engl J Med. 1999;341(20):1552-3.

11. Mostafa SRA, El Zeiny NAM, Tayel SES, Moubarak El. What do medical students in Alexandria know about female genital mutilation? East Mediterr Health J. 2006;12 SUPPL 2:S78-92.

12. Rasheed SM, Abd-Ellah AH, Yousef FM. Female genital mutilation in Upper Egypt in the new millennium. Int J Gynaecol Obstet. 2011;114(1):47-50.

13. Refaat A. Combating the Medicalization of Female Genital Cutting in Egypt: Steps on the long road for its eradication. Suez Canal University; 2007.

14. Refaat A. Medicalization of female genital cutting in Egypt. East Mediterr Health J. 2009:15(6):1379-88.

15. Newman C, Nelson D. Mali: FGC. Counseling and Advocacy to Abandon Female Genital Cutting. North Carolina: PRIME II. IntraHealth International, Inc; 2003.

16. Adekanle A, Isawumi A, Adeyemi A. Health Workers. Knowledge of and Experience with Female Genital Cutting in Southwestern, Nigeria. Sierra Leone J Biomed Res. 2011:3(3):84-8.

17. Ashimi A, Aliyu L, Shittu M, Amole T. A multicentre study on knowledge and attitude of nurses in northern Nigeria concerning female genital mutilation. Eur J Contracept Reprod Health Care. 2014;19(2):134-40.

18. Ali AA. Knowledge and attitudes of female genital mutilation among midwives in Eastern Sudan. Reprod Health. 2012;9:23.

19. Widmark C, Tishelman C, Ahlberg BM. A study of Swedish midwives' encounters with infibulated African women in Sweden. Midwifery. 2002 18(2):113-25.

20. Zaidi N, Khalil A, Roberts C, Browne M. Knowledge of female genital mutilation among healthcare professionals. J Obstet Gynaecol. 2007;27(2):161-4.

21. Elliott C, Creighton SM, Barker M, Liao LM. A brief interactive training for health care professionals working with people affected by "female genital mutilation": initial pilot evaluation with psychosexual therapists. Sex Relat Ther. 2016;31(1):70-82.

22. Purchase TC, Lamoudi M, Colman S, Allen S, Latthe P, Jolly K. A survey on knowledge of female genital mutilation guidelines. Acta Obstet Gynecol Scand. 2013;92(7):858-61.

23. Relph S, Inamdar R, Singh H, Yoong W. Female genital mutilation/cutting: knowledge, attitude and training of health professionals in inner city London. Eur J Obstet Gynecol Reprod Biol. 2013;168(2):195-8.

24. Moeed SM, Grover SR. Female genital mutilation/cutting (FGM/C): survey of RANZCOG fellows, diplomates \& trainees and FGM/C prevention and education program workers in Australia and New Zealand. Aust N Z J Obstet Gynaecol. 2012;52(6):523-7.

25. Sureshkumar P, Zurynski Y, Moloney S, Raman S, Varol N, Elliott EJ. Female genital mutilation: Survey of paediatricians' knowledge, attitudes and practice. Child Abuse Negl. 2016;55:1-9.

26. Cappon S, L'Ecluse C, Clays E, Tency I, Leye E. Female genital mutilation: knowledge, attitude and practices of Flemish midwives. Midwifery. 2015 31(3):e29-35.
27. Leye E, Ysebaert I, Deblonde J, Claeys P, Vermeulen G, Jacquemyn Y, et al. Female genital mutilation: knowledge, attitudes and practices of Flemish gynaecologists. Eur J Contracept Reprod Health Care. 2008;13(2):182-90.

28. Unicef, Suisse. Les mutilations génitales féminines en Suisse. Zurich: Comité suisse pour I'UNICEF; 2012.

29. Unicef, Suisse, Santé Sexuelle Suisse. La période qui entoure la naissanceune charnière de la prévention. Zurich; 2016.

30. Hess RF, Weinland J, Saalinger NM. Knowledge of female genital cutting and experience with women who are circumcised: a survey of nurse-midwives in the United States. J Midwifery Womens Health. 2010;55(1):46-54.

31. Jacoby SD, Smith A. Increasing certified nurse-midwives' confidence in managing the obstetric care of women with female genital mutilation/ cutting. J Midwifery Womens Health. 2013;58(4):451-6.

32. Kaplan-Marcusan A, Toran-Monserrat P, Moreno-Navarro J, Castany Fabregas MJ, Munoz-Ortiz L. Perception of primary health professionals about female genital mutilation: from healthcare to intercultural competence. BMC Health Serv Res. 2009;9:11.

33. Tamaddon L, Johnsdotter S, Liljestrand J, Essen B. Swedish health care providers' experience and knowledge of female genital cutting. Health Care Women Int. 2006:27(8):709-22.

34. Onuh SO, Igberase GO, Umeora JO, Okogbenin SA, Otoide VO, Gharoro EP. Female genital mutilation: knowledge, attitude and practice among nurses. J Natl Med Assoc. 2006;98(3):409-14.

35. UNFPA. Baseline Study on Midwives Knowledge, Attitudes and Practices on FGC Prior to their Enrolment in Midwifery Schools' New Curriculum. 2016.

36. Doucet $\mathrm{MH}$, Pallitto C, Groleau D. Understanding the motivations of healthcare providers in performing female genital mutilation: an integrative review of the literature. Reprod Health. 2017;14(1):46.

37. Dawson AJ, Turkmani S, Varol N, Nanayakkara S, Sullivan E, Homer CS. Midwives' experiences of caring for women with female genital mutilation: Insights and ways forward for practice in Australia. Women Birth. 2015;28(3):207-14.

\section{Submit your next manuscript to BioMed Central and we will help you at every step:}

- We accept pre-submission inquiries

- Our selector tool helps you to find the most relevant journal

- We provide round the clock customer support

- Convenient online submission

- Thorough peer review

- Inclusion in PubMed and all major indexing services

- Maximum visibility for your research

Submit your manuscript at www.biomedcentral.com/submit
) Biomed Central 